\title{
Review Article \\ Progress and Challenges toward the Development of Vaccines against Avian Infectious Bronchitis
}

\author{
Faruku Bande, ${ }^{1,2}$ Siti Suri Arshad, ${ }^{1}$ Mohd Hair Bejo, ${ }^{1,3}$ \\ Hassan Moeini, ${ }^{4}$ and Abdul Rahman Omar ${ }^{1,3}$ \\ ${ }^{1}$ Department of Veterinary Pathology and Microbiology, Faculty of Veterinary Medicine, Universiti Putra Malaysia (UPM), \\ 43400 Serdang, Selangor, Malaysia \\ ${ }^{2}$ Department of Veterinary Services, Ministry of Animal Health and Fisheries Development, PMB 2109, Usman Faruk Secretariat, \\ Sokoto 840221, Sokoto State, Nigeria \\ ${ }^{3}$ Laboratory of Vaccine and Immunotherapeutics, Institute of Bioscience, Universiti Putra Malaysia (UPM), 43400 Serdang, \\ Selangor, Malaysia \\ ${ }^{4}$ Department of Virus-Associated Tumours (F100), German Cancer Research Centre, Im Neuenheimer Feld 242, \\ 69120 Heidelberg, Germany
}

Correspondence should be addressed to Siti Suri Arshad; suri@upm.edu.my

Received 27 December 2014; Revised 20 March 2015; Accepted 23 March 2015

Academic Editor: Peirong Jiao

Copyright (C) 2015 Faruku Bande et al. This is an open access article distributed under the Creative Commons Attribution License, which permits unrestricted use, distribution, and reproduction in any medium, provided the original work is properly cited.

\begin{abstract}
Avian infectious bronchitis (IB) is a widely distributed poultry disease that has huge economic impact on poultry industry. The continuous emergence of new IBV genotypes and lack of cross protection among different IBV genotypes have been an important challenge. Although live attenuated IB vaccines remarkably induce potent immune response, the potential risk of reversion to virulence, neutralization by the maternal antibodies, and recombination and mutation events are important concern on their usage. On the other hand, inactivated vaccines induce a weaker immune response and may require multiple dosing and/or the use of adjuvants that probably have potential safety risks and increased economic burdens. Consequently, alternative IB vaccines are widely sought. Recent advances in recombinant DNA technology have resulted in experimental IB vaccines that show promise in antibody and T-cells responses, comparable to live attenuated vaccines. Recombinant DNA vaccines have also been enhanced to target multiple serotypes and their efficacy has been improved using delivery vectors, nanoadjuvants, and in ovo vaccination approaches. Although most recombinant IB DNA vaccines are yet to be licensed, it is expected that these types of vaccines may hold sway as future vaccines for inducing a cross protection against multiple IBV serotypes.
\end{abstract}

\section{Background}

Avian infectious bronchitis (IB) is an economically important poultry disease affecting the respiratory, renal, and reproductive systems of chickens. Although IB was first identified in North Dakota, USA [1], epidemiological evidences confirmed the circulation of several IBV serotypes in different parts of the world. Currently, both classic and variant IBV serotypes have been identified in most countries, thus making IB control and prevention a global challenge $[2,3]$. The disease is associated with huge economic losses resulting from decreased egg production, poor carcass weight, and high morbidity. Mortality rate could be high in young chickens especially with other secondary complications such as viral and bacterial infections [4].

Vaccination has been considered to be the most cost effective approach to controlling IBV infection [5]. However, this approach has been challenged by several factors including the emergence of new IBV serotypes (currently over 50 variants) that show little or no cross protection [6]. Importantly, some IBV strains to which vaccines become available might disappear as new variants emerged and thus necessitate the development of new vaccines [5]. Until recently, most IBV vaccines are based on live attenuated or killed vaccines derived from classical or variant serotypes. These vaccines are developed from strains originating from the USA such 


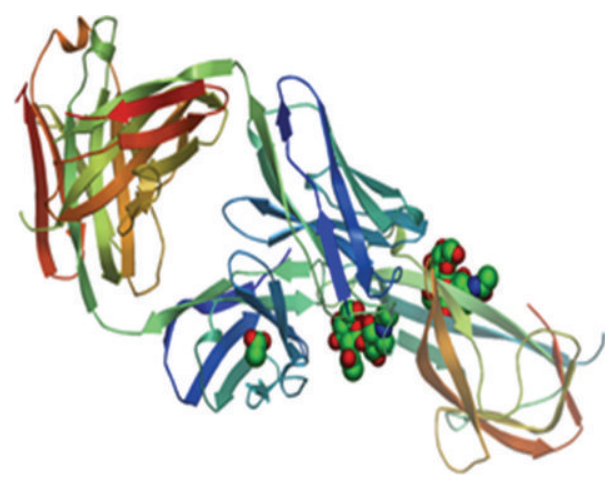

(a)

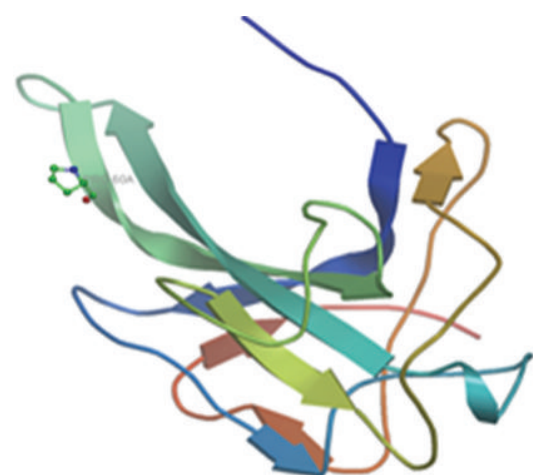

(b)

FIGURE 1: Predicted 3-dimensional structure of S1-glycoprotein (a) and nucleocapsid protein (b), determinants of Massachusetts strain of avian infectious bronchitis virus. Structures are drawn using SWISS homology modeller available online at http://swissmodel.expasy.org/.

as M41, Ma5, Ark, and Conn and Netherlands, for example, H52 and H120, as well as European strains such as 793/B, CR88, and D274. However, studies have shown that vaccines against these strains often lead to poor immune response especially against local strains. Live attenuated IB vaccines have also been shown to contribute to the emergence of new pathogenic IBV variants $[7,8]$. Notably, changes in geographical distribution and tissue tropism have been observed in QX-like strains that initially emerged in China and spread to cause great economic loss to poultry farmers in Asia [9], Russia [10], and Europe [11-14]. This review is aimed at describing progress and challenges associated with IBV vaccine development. Some aspects of viral-induced immune responses are discussed.

\section{Review}

2.1. Aetiology and Genome Characteristics. Avian infectious bronchitis virus (IBV), together with Turkey coronavirus and Beluga whale coronavirus, belongs to a Gammacoronavirus subgroup, family Coronaviridae, order Nidovirales. Although antigenically different, members of Coronaviridae family such as SARS and MERS coronavirus share common structural protein organisation. Coronaviruses genome is made up of a single stranded enveloped RNA that measures from 27 to $32 \mathrm{~kb}$, making them the largest of the RNA viruses [15]. Particularly, IBV genome has an average diameter of 80-120 nm and a typically large club of $20 \mathrm{~nm}$, with heavily glycosylated spike projections. Four different genes encoding for the structural proteins are found in IBV genome. These are designated as spike $(\mathrm{S})$, envelope $(\mathrm{E})$, matrix $(\mathrm{M})$, and nucleocapsid $(\mathrm{N})$. The structural protein genes are also interspaced by genes coding for nonstructural and accessory proteins, arranged in the order of $5^{\prime}$ to $3^{\prime}$ directions as UTR-1a/1ab-S3a-3b-E-M5a$5 b-N-3^{\prime}$-UTR-poly(A) [16]. Of the structural protein genes, the $\mathrm{S} 1$ and $\mathrm{N}$ proteins contain epitopes responsible for host immune response (Figure 1).

2.2. Spike Glycoprotein. The S-protein is heavily glycosylated transmembrane protein that spanned from 1,160 amino acids, giving rise to $150-200 \mathrm{kDa}$. It possessed a cleaved signal sequence, one transmembrane domain, and a short C-terminal tail [17]. IBV S-protein is made up of 3400 nucleotides posttranslationally cleaved into S1 (520 AAS residue) at the amino terminal and S2 (625 AAS residue) at the carboxyl terminal. The two glycosylated proteins (S1 and S2) are anchored in the hydrophobic region near the carboxylic part of the S2 and cleaved by furin or its related enzymes in the Golgi complex $[18,19]$. Typically, S1glycoprotein plays a role in receptor binding, while the S2 contributes aids in the fusion of the virus [20]. Of the two S-glycoprotein genes, the S1-gene is the important immunogenic component and contained epitopes responsible for neutralizing antibody $[21,22]$. It also determines receptor binding as well as membrane fusion via virus-to-cell and cellto-cell interactions [20].

2.3. The Nonstructural Genes' $3 a, 3 b, 5 a$, and $5 b$ Proteins. The IBV genome possesses two small nsp genes, 3 and 5, that express three $(3 a, 3 b$, and $3 c[E])$ and two (5a and $5 b)$ gene products, respectively. The $3 \mathrm{a}, 3 \mathrm{~b}, 5 \mathrm{a}$, and $5 \mathrm{~b}$ proteins of IBV show a unique sequence characteristic when compared to members of group I and II coronaviruses [23]. Although the specific function of small protein remains unknown these genes are thought to contribute to virus virulence $[23,24]$. Studies on the function of $5 \mathrm{a}-\mathrm{ns}$ segment using reverse genetics have identified a possible link between ns-protein and virus virulence; however, their contribution to virus replication may be less relevant [25].

2.4. Matrix Protein. The coronavirus matrix protein (Mprotein) slightly protrudes to the surface and is situated between 220 and 262 aa, which is glycosylated on the $\mathrm{N}$ terminal domain [26]. Although members of group 2 coronavirus are $\mathrm{O}$-glycosylated, IBV and members of group 1 coronaviruses are glycosylated with $\mathrm{N}$-linked oligosaccharide molecules [27]. The role of glycosylation of M-protein is still not clear; however, using the MHV model, it was found that cell infected with MHV containing N-glycosylated 
M-protein induces a better interferon response compared to those infected with O-glycosylated M-protein, while nonglycosylated M-protein MHV infection resulted in a very poor interferon response $[28,29]$.

2.5. Nucleocapsid Protein. During viral replication, direct interaction occurs between $\mathrm{N}$ - and M-proteins [30] and similarly between $\mathrm{N}$ and nsp3a [31]. Similarly, an indirect interaction has been suggested between $\mathrm{N}$ and $\mathrm{S}$ as a result of S-M-protein segments interaction [30]. Nucleocapsid protein functionally binds with the genomic gRNA to form a helical ribonucleoprotein complex (RNPC), thus aiding transcription, replication, translation, and packaging of the viral genome during the replication process [32]. Coronavirus $\mathrm{N}$-protein also plays role in the induction of cytotoxic $\mathrm{T}$ lymphocytes response due to the presence of CTL-inducing epitopes located at its carboxylic terminus [33, 34]. In addition, novel linear B-cells epitope peptides have been mapped within the nucleocapsid N-terminal domain [35].

2.6. Small Envelope Protein. The IBV small envelope "E" protein is a scant protein and contains highly hydrophobic transmembrane $\mathrm{N}$-terminal and cytoplasmic C-terminal domains. This protein has been suggested to be associated with viral envelope formation, assembly, budding, ion channel activity, and apoptosis [36, 37].

2.7. Serotypes and Strain Variations. Currently, there are several classical and variant IBV strains that have spread in different countries [38]. These strains may be closely or distantly related as represented in the phylogenetic tree (Figure 2). Variation may arise due to a small change as little as $5 \%$ in the S1 amino acid composition and may lead to alteration in cross protection among closely related serotypes. Thus, the nature of IBV-S1 sequences is taken into consideration in designing novel control strategies $[39,40]$. Despite being first identified in USA, the classical M41 serotype and the Dutch H120 serotype are the most widely used vaccine viruses [3]. However, the World Organization for Animal Health (OIE) recommended that the distribution of IBV serotypes should influence the choice of vaccine for use in each geographic region. For example, M41, Arkansas, and Connecticut are common in USA, while 4/91 (793/B, CR88) and D274 are predominately found in Europe [41, 42]. Recently, the Chinese QX variants have emerged to cause outbreaks in Europe, Asia, the Middle East, and Africa, demonstrating a shift in geographical distribution and importance of the QX-like genotype. This variation in strain distribution is indeed a challenge to IBV control programmes. It is expected that other serotypes will continue to emerge as a result of RNA mutation and recombination that lead to viral selection pressure $[3,43]$. Other local variants are common within specific regions and/or countries, but their global distribution is yet to be ascertained [44].

2.8. RNA Mutation and Recombination. Mutation and recombination are important phenomena that shaped coronavirus

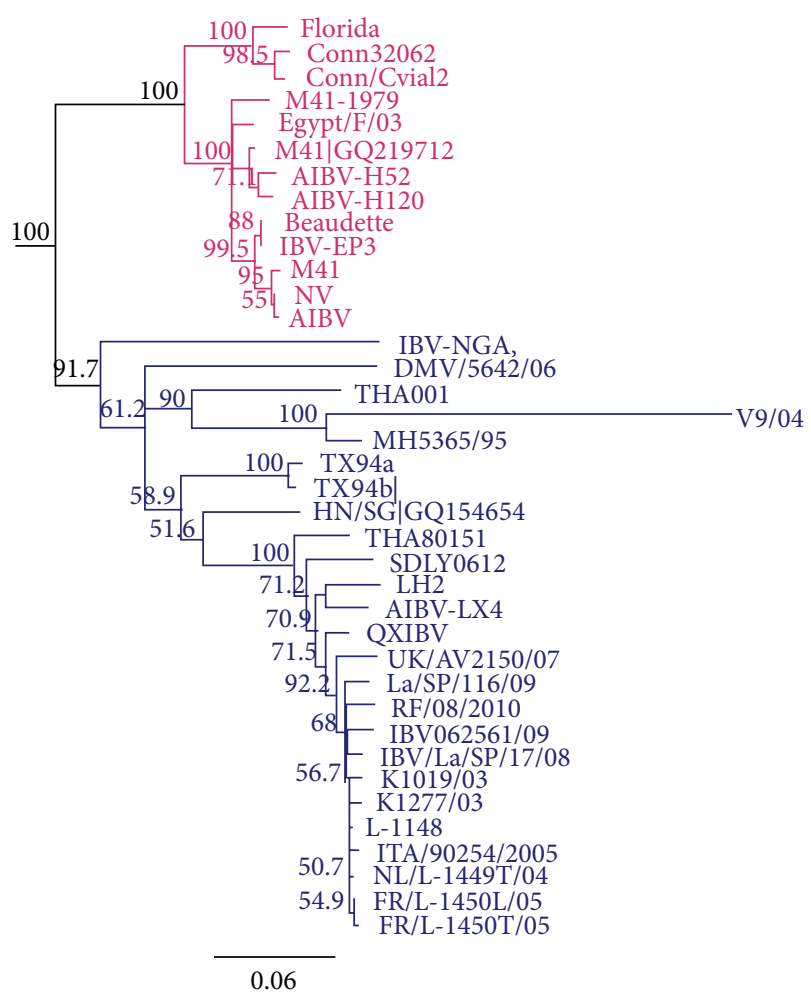

FIGURE 2: Neighbour-joining phylogenetics showing relationship in S1glycoprotein of classical (pink) and variant (blue) IBV strains. The tree reliability was assessed using 1000-bootstrap confidence and branching pattern is supported by $91.7-100 \%$ bootstraps values and associated taxa show $82 \%$ pairwise identity. Phylogenetic analysis was carried out using Geneious software version R8.

viral genomes [45]. As with most RNA viruses, mutation and recombination are two important events that alter or shape coronavirus viral genome. Consequently, a viral subpopulation may evolve as a result of these important genetic events $[16,43,46]$. Although it is difficult to ascertain how IBV genome evolved, three major theories have been hypothesised as follows: (i) the lack of RNA polymerase proofreading activity could lead to errors in RNA genome which in turn result in mutation especially in the S1 spike gene (nucleotide insertions, deletions, or point mutations). (ii) The use of vaccines especially the live attenuated vaccines type or presence of multiple infections with different IBV serotypes contributes to recombination process that favours the emergence of new IBV variants [47]. Mixture between various genetic mutants of the same coronavirus strains has been shown to generate quasispecies viruses [48, 49]. Mutations, in the hypervariable S1 domain, may affect viral subpopulation and result in new viruses with different pathogenicity as well as virulence $[43,46]$. It was found that regions encoding for the nonstructural proteins 2,3 , and 16 , as well as the spike glycoprotein, exhibited the highest degree of recombination [50]. Likewise, experimental passaging of IBV in the presence of other immunosuppressive viruses such as Marek's disease virus, chicken anaemia virus, and infectious bursal disease, has been suggested to affect IBV evolutionary dynamics [51]. 


\section{Host Immune Response against Infectious Bronchitis Virus}

3.1. Passive Immunity. Maternally derived antibodies (MDAs) are important components of early protection against infectious agents. It was shown that MDAs last from days to weeks, depending on the virus strain. Approximately $97 \%$ of birds with MDAs are likely to be protected against IBV infection at day one of age. However, this protection may decline to $<30 \%$ by age of 7 days, thus demonstrating a limited duration of protection [52]. Adoptive transfer of antibody also has been reported to induce $\alpha \beta$ associated CD8+ T-lymphocytes that protected chickens from infection with virulent IBV strain, thus signifying the role of passive immunity in IBV infection [52].

3.2. Innate Immune Responses. The innate immune response is important as the body's first line of defence. This response relies on pathogen-associated molecular patterns (PAMPs) through specific pattern-recognition receptors (PRRs) that are displayed on immune cells such as dendritic cells, macrophages, lymphocytes, and several nonimmune cells such as endothelial cells, mucosal cells, and fibroblasts. Importantly, the type I interferon response which is characterized by the secretions of chicken interferon alpha and interferon beta provides efficient and rapid response against viral replication through the activation of macrophages and natural killer cells which further lead to the induction of adaptive immune response. The type II interferon response which is characterized by interferon gamma secretion is predominantly produced by the activated NK cells, dendritic cells, and CD4+ CD8+ T-lymphocytes. This will further enhance leukocytes adhesion, cause NK cells activation, and increase antigen presentation on the surface of APCs (macrophages and dendritic cells) and subsequently causes the expression of MHC-I molecules and the development of adaptive response [53].

Specifically, the toll-like receptors (TLRs) such as the TLR4, TLR5, TLR15, and TLR16 are involved in the innate sensing during viral infections [54]. As with SARS virus and mouse hepatitis virus (MHV), significant upregulation of TLR4 has been observed in IBV infection, suggesting its role in coronavirus infection irrespective of the host species involved [55]. In IBV infection, innate immune response has been associated with the secretion of type I interferon in the trachea, lungs, and kidney shortly after contact with the virus [56]. This response however depends on the virulence of IBV as well as the host adaptability of the viral strain [57]. Chicken type I interferons play important roles in the inhibition of viral replication probably through interaction with TLRs molecules and pattern-recognition receptors (PPRs) that are crucial in detecting viral entry into the cells and for bridging innate and adaptive immune responses [58-60]. This is supported by the alteration in TLRs expression, especially TLR2, TLR3, and TLR7 observed in the trachea, lungs, and kidney following IBV infection $[60,61]$.

Administration of synthetic oligodeoxynucleotides (CpG ODNs) led to a significant increase in the expression of interferon gamma (IFN-gamma), interleukin 1-beta, IL-6, IL-8, and oligoadenylate synthetase [62]. Similarly, transcriptional analysis and cytokine profiling revealed that IL$1 \beta$, MIP-1 $\beta$, and IFN signalling pathways may serve as a bridge between innate and adaptive immunities following IBV vaccination [63]. The mechanism through which IBV induces antiviral responses is very complex. However, it was suggested that involvement of the JAK-STAT pathway and upregulation of genes related to immune response such as STAT1, MYD88, IRF1, and NFKB2 are crucial to the host immune response whereas upregulation of genes related to viral protein synthesis such as elF1 helps the virus to evade immune defences $[60,64]$.

3.3. Humoral Response. Humoral immune response is associated with the inhibition of viral replication and has been shown to correlate with IBV-specific antibody titre. Antibody response following IBV vaccination has been demonstrated in serum, tracheal swabs, and lacrimal secretion [6]. Studies have shown that both systemic (IgM and IgG) and mucosal (IgA) antibodies are essential determinants for effective clearance of the circulating virus [65]. In addition, IgA, being the major immunoglobulin molecule for mucosal response, plays a role in antibody homing at tracheal or other mucosal points of viral entry [66]. Remarkably, IgM appeared 5 days after infection (dpi), peaked at days 8-10, and disappeared around 18 days after infection, while local responses correlate with increased IgG levels and subsequent clearance of the virus [56].

3.4. Cell-Mediated Immune Response. The N-gene specific protein response is associated with the induction of CTLs that are responsible for clearance of IBV-infected cells [34, 67]. The CTLs response peaked after 10 days, correlating with a decrease in clinical signs and viral clearance from lungs [68]. A significant increase in the CD4+ and CD8+ T-cells has been reported following vaccination with S1-gene specific IBV vaccines; thus S1-gene importantly plays role in cellmediated immune response [69]. Viral clearance may be associated with an increase in the expression of granzymes A during primary IBV infection and subsequent activation of NK cells that aid in direct or targeted killing of IBV-infected cells [70].

3.5. Mucosal Immune Response. Despite advances in the understanding of mucosal immunology, much is yet to be learned about mucosal immune responses in birds. IBV replication at Harderian glands (HG), conjunctiva influences the development of the mucosal immune response which is characterized by the secretions/production of the specific IgA. This response has been further linked with the lymphoid expansion at the head associated lymphoid tissues (HALTs) and subsequent induction of CTL response [71]. Ocular vaccination of chickens with a recombinant nucleocapsid protein $(\mathrm{rN})$ and recombinant S1-protein- ( $\mathrm{rS}-)$ based IBV vaccine (via eye drop) induced significant cell-mediated immune responses without booster vaccination or adjuvants. Birds vaccinated with such vaccines were shown to be protected 
against infection with virulent virus strain, though the level of IgA in the mucosa was higher in positive control birds receiving only H120 live attenuated vaccine [72].

\section{Vaccines against Infectious Bronchitis Virus}

4.1. Live Attenuated Vaccines. Live attenuated IB vaccines are the first generation IBV vaccines used to control IBV infection in the field. These vaccines are commercially available for application via drinking water or by coarse spray at 1 day or within the first week of age. Since the duration of immunity following live attenuated vaccines is short, booster vaccination is carried out with the same or combinations of other strains, 2-3 weeks after prime vaccination [73]. Most of the commercially available live attenuated vaccines are derived from virulent strains such as Massachusetts-based M41 serotype and the Dutch H52 and H120 strains, although some strains with regional or local impact have been used in different parts of the world [74-76].

Live vaccines often are used in broilers and as boosters for breeders. However, variation may exist among countries on the type of IBV vaccine strain approved for use. This should be guided by epidemiological knowledge of the locally or regionally prevalent strains. For example, in USA, the M41, H120, Arkansas, Delaware, Florida, and JMKderived vaccines are used frequently. In Australia, the B and $\mathrm{C}$ strains are used; in UK/Europe vaccine strains include M41, 4/91, and CR88. In Netherlands, vaccination using D274 and D1466 is commonly practiced [74]. For logistics and economic reasons, some commercially available live attenuated IBV vaccines have been combined with other virus vaccines such as those against Newcastle disease virus, Marek's disease virus, and infectious bursal disease virus (IBDV). However, it is not clear whether the combination may influence immune response to the combined antigen [77]. Few examples of commercially available live attenuated vaccines include Nobilis IB-Ma5 (MSD Animal Health, UK) from Mass serotype; AviPro IB H120 which is also considered as Mass serotype based vaccine from Dutch H120 strain (Lohmann Animal Health, Germany); Nobilis 4-91 (MSD Animal Health, UK); Gallivac CR88 (Merial, USA) from European strains. Live attenuated vaccine, POULVAC IB QX, has also been produced against the recently endemic QX-like IBV strains (Pfizer, France).

Some of the limitations of live attenuated viral vaccines include reversion to virulence, tissue damage, and interference by MDA. Tissue damage due to live vaccines may lead to pathological disorders or secondary bacterial infections, especially in day-old chick [78]. Evidence has shown that despite efforts to reduce viral virulence by using 52 or 120 passages to produce $\mathrm{H} 52$ and H120 IBV vaccines, respectively, these vaccines potentially cause considerable pathology of the trachea and may lead to a severe outbreak in the field $[79,80]$. Another limitation of live attenuated IBV vaccines is potential recombination between vaccine strains and virulent field strains, leading to the emergence of new IBV serotypes $[7,75,81]$. In one study, vaccination with live attenuated H120 vaccines was shown to encourage viral spread among broiler chickens, thus potentially supporting virus transmission and persistence [82]. To reduce problems associated with vaccine reversion, researchers explore the options of using reverse genetic technology to create vaccine virus that is potentially apathogenic in the host, but capable of replication and inducing immune response. This has been shown in the case of Beaudette virus carrying the S1-gene of virulent M41 IBV strains $[83,84]$.

4.2. Inactivated or Killed Vaccines. Inactivated or killed vaccines have been used either alone or in combination with live attenuated IBV vaccines [85]. These vaccines usually are administered by injection to layers and breeders at 13 to 18 weeks of age. Since inactivated vaccines do not replicate, they are unlikely to revert and cause pathological effects. However, compared to live attenuated vaccines, killed vaccines alone induce shorter immune response characterized by antibody production but not T-cell-mediated responses [34, 86]. Therefore, inactivated vaccines in most cases require priming with live attenuated vaccines, large doses of adjuvants, and/or multiple vaccinations. This may increase the costs associated with vaccine development and marketing, thus limiting their applications [5]. Being injectable, administration of killed vaccines is either difficult or impracticable in large poultry setting. Likewise, issues of injection-site reactions may also lead to carcass rejection or reduction in value [87].

\subsection{Recombinant Vaccines}

4.3.1. Viral Vector-Based Vaccines. The use of viral vectors to deliver gene(s) of interest has been studied extensively. Remarkably, the ability of adenovirus vector to persist in cells without causing pathology as well as their tropism to various dividing and nondividing cells allows sustained antigen release. It is also possible to package and express different immunogenic protein subunits in vector-based vaccines without the necessary use of a whole virulent organism [88]. Experimental recombinant vector vaccines have been developed against IBV. These vaccines were shown to induce significant increase in the immune response and protect against IB disease [69].

Although advances in viral vector vaccines seem promising in providing effective immune response and for reducing the problems associated with RNA mutation as seen in live attenuated IBV vaccines [89], this technology does have limitations that include issue of preexisting immunity or maternally derived immunity that interferes with the live vector itself and reduces the uptake of the antigen by the antigen presenting cells and consequently the transgene expression as well as specific immune response [90]. Lack of proper protein folding and glycosylation in the host system and posttranslational modifications may alter the conformation and epitope arrangement that affect the immunogenicity and efficacy of the vaccine. These factors are currently given special attention in design and selection of recombinant IBV vaccines [91]. Recent study using a recombinant adenovirus vaccine containing IBV-S1-glycoprotein reported a significant antibody response that conferred $90-100 \%$ protection, against tracheal 
lesions following homologous and heterologous challenge with Vic S (serotype B) or N1/62- (serotype C-) IBV strains [69].

Different protein antigens have been coexpressed with genes encoding for genetic adjuvants for an enhanced immune response. In this regard, Shi et al. [92] show that a fowl pox virus vaccine expressing IBV-S1-gene and chicken interferon- $\gamma$ gene [rFPV-IFN $\gamma$ S1] enhances humoral and cell-mediated immune responses that protect chickens against homologous and heterologous challenge with LX4, LHLJ04XI, and LHB IBV strains. Expression of IBV-S1-gene with chicken IL-18 in a recombinant fowl pox virus vector produced a significant increase in antibody titre, CD4+, and CD8+ responses. Similarly, expression of IL-18 with IBV-S1gene using a fowl pox virus vector (rFPV-S1/IL18) resulted in $100 \%(20 / 20)$ protection, compared with only $75 \%(15 / 20)$ protection, rates in chickens receiving a construct containing S1 alone [93].

Oral immunization of mice with adenovirus vector was shown to circumvent neutralization of the vector by preexisting or maternally derived antibody [94]. Interestingly, adenovirus vector vaccines have been shown to be promising for use in poultry oral vaccines. Oral immunization therefore has several advantages in poultry medicine such as the ease of application and reduction in stress associated with injection handling. Although vector-based oral vaccine may lead to an adequate transgene specific antibody response, improvements are needed for optimal T-cell response. Modifications of vector-based vaccines such as dose escalation, nanoparticle coating, use of dual vectors (e.g., combination of pox and adenovirus-based vectors) and/or swapping of adenovirus hexon gene have been attempted to circumvent the effect of preexisting immunity but with some degree of success and reported toxicity in other infection models [88].

Lentivirus vectors are finding ways into veterinary vaccines, although lentivirus-based IB vaccines are uncommon [95]. Overall, only simultaneous comparative studies will assist in understanding the advantages of one vector over others.

4.3.2. Subunit and Peptide-Based Vaccines. This technology requires the use of a segment or parts of the viral protein to induce specific immune response. While subunit vaccines are derived from pathogen protein or polysaccharide, peptide vaccines are made from pathogen peptides or a portion of the genome coding for immunogenic epitope [95]. Epitope within S1- and N-gene has been targeted for the induction of neutralizing antibodies as well as CTL responses, respectively [22]. For example, a study has demonstrated that synthetic epitope peptide corresponding to S20-S255 reacted well with polyclonal antibodies against various IBV strains, thus demonstrating its potential applications for broad-based IB vaccines [96]. These broad vaccines have also been mapped between 19 and 69 as well as 250 AAS sequences within the receptor binding domain whose $\mathrm{N}$-terminal plays role in viral entry [97].

Although, at experimental stages of development, synthetic and peptide vaccines have been shown to be promising in the control of IBV, some researchers have focused on developing multiepitope peptide vaccines for use against wide range of IBV serotypes. Recently, Yang et al. [98] have developed an IBV vaccine based on the multiple epitopes from S1- and N-protein genes. Expression analyses and immunization study using the designed synthetic peptides yielded significant humoral and cell-mediated immune responses that resulted in $>80 \%$ protection after challenge with virulent virus. In another development, a Lactococcus lactis bacterial system was used to deliver peptide vaccines orally and this approach was also reported to induce mucosal immune response $[99,100]$.

4.3.3. Plasmid DNA Vaccines. Unlike recombinant vectorbased vaccines involving a live vector, DNA vaccines use a plasmid containing the gene(s) that code for an immunogenic protein(s) of interest [101]. Until recently, no licensed poultry DNA vaccine is commercially available; however, this technology has gained considerable attention, and several products are at various developmental or experimental trial stages [102]. A DNA vaccine designated pDKArkS1-DP has been developed, based on the S1-genes of Arkansas IBV serotypes. Vaccination via in ovo route, followed by immunization with a live attenuated vaccine at 2 -week intervals, resulted in a significant immune response and $100 \%$ protection against clinical disease. On the other hand, birds receiving either in ovo DNA vaccination alone or live attenuated vaccine alone had $\leq 80 \%$ protection after challenge with a virulent IBV strain [103].

Apart from in ovo DNA vaccinations, other novel approaches have been evaluated. For example, intramuscular injection of a liposome-encapsulated multiepitope DNA vaccine designed from $\mathrm{S} 1, \mathrm{~S} 2$, and $\mathrm{N}$ regions resulted in increased numbers of $\mathrm{CD} 4+, \mathrm{CD} 3+$, and $\mathrm{CD} 8+, \mathrm{CD} 3+$ cells, and a protective immune response in $80 \%$ of the immunized birds. Some of the advantages of epitope-based vaccines include the ability to package several immunogens in a small delivery system for targeted antibody and CTL responses [104].

Enhancement of a vaccine-induced immune response was achieved by coadministration of a DNA vaccine encoding for IBV nucleocapsid or S1-glycoprotein genes with IL-2 [105] or chicken granulocyte-macrophage stimulating factors (GM-CSF), respectively [106]. In both cases, significant increase in the humoral and cell-mediated immune responses has been reported. However, S1-encoded DNA vaccines resulted in a better immune response and accorded 95\% protection that was slightly higher compared to the $\mathrm{N}$ gene-encoded plasmid. In another study, a multivalent IBVDNA vaccine encoding for the S1-, N-, and M-proteins was developed $[98,107]$. The efficacy and protective capacity of each gene specific IBV-DNA vaccine were shown to improve when a cationic liposome carrier was used. A similar result was obtained through boosting with an inactivated vaccine [107].

DNA vaccines have some limitations including route of administration, since most DNA vaccines are administered by injection, thus making their application difficult in large commercial poultry [108]. However, challenges related to 


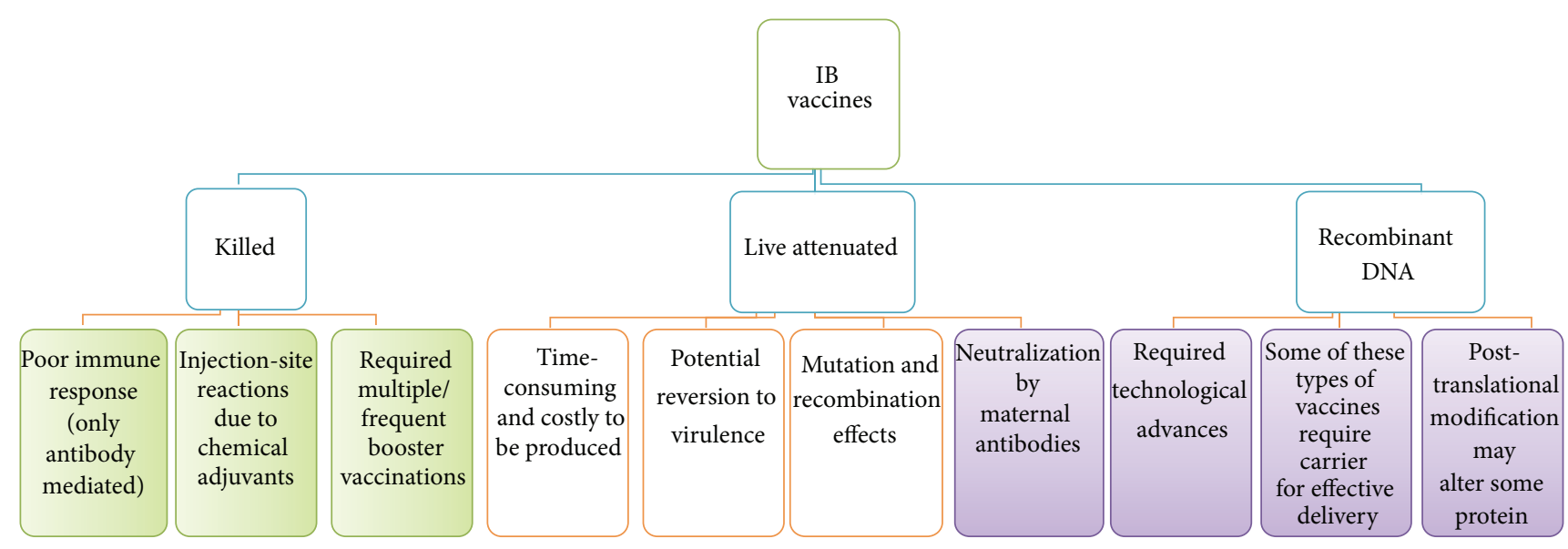

FIGURE 3: Summary of major IB vaccines and important limitations associated with the vaccine types.

the route of DNA vaccines administration could be overcome using in ovo DNA vaccination at the hatchery [103] or by giving vaccines in drinking water or as a spray vaccine. A nanoparticle-mediated DNA delivery will assist in protecting the vaccine against enzymatic degradation and enhances their availability at mucosal surfaces for mucosal response [71]. Since DNA vaccines could be used in the presence of maternal antibodies, their usage in poultry could be used to overcome challenges associated with vaccination of young chicks against IBV infection. Other advantages of DNA vaccines include the induction of both antibody and T-cells immune response, safety, ability to express multiple proteins, thermostability, and cost of production. They could be produced within a short period, thus enabling handling of the emerging virus threat. Moreover, modifications with cytokines adjuvant favour their choice in the control of infectious diseases of poultry [109].

4.4. Reverse Genetic Vaccines. A reverse genetic vaccine involved a new technology of manipulating one or more viral genes. Recently, this technology has been employed to modify IBV vaccine candidates $[24,110,111]$. For example, a recombinant, BeauR-IBV vaccine has been constructed recently by substituting the antigenic S1-glycoprotein of an apathogenic Beau-IBV strain with another S1-gene from pathogenic M41 and European 4/91 strains, respectively [112, 113]. These changes resulted in protective immune responses without making the new BeauR strain pathogenic [113, 114]. Similarly, Zhou et al. [84] have constructed a modified H120 (R-H120) virus that was found to retain some of its biological activities when rescued after 5 passages in embryonated chicken eggs. Interestingly, a vaccine using this strain has been reported to elicit a high level of haemagglutination inhibition (HI) antibody titre and a comparable protection rate compared with an intact H120-vaccinated group. The future of reverse genetic vaccines may be born out of their potentials to abrogate issues of reversion to virulence as reported with live attenuated vaccines. Development of reverse genetic IBV vaccines that may overcome neutralization in the presence of preexisting immunity, although very difficult, will surely revolutionise the use of reverse genetic-based live attenuated IBV vaccines. But whether these newer generation vaccines will increase or reduce the chances of mutation and viral selection pressure requires further studies. A summary of important limitations associated with IB vaccines is presented in Figure 3.

\section{Expression and Delivery Systems}

5.1. Vaccine Expression System. In recombinant or subunit vaccines, consideration is given to the presence or absence of posttranslational modification associated with the vaccine antigen. However, thorough knowledge of the chemistry and biology of the immunodominant antigen is needed to guide selection of a suitable expression system, since outcomes may differ from bacteria, yeast, mammalian, baculovirus, and plant expression systems [91]. Different expression systems have been used to generate recombinant protein antigen. An attempt, using a vaccinia virus-based IBV vaccine, failed to produce antigen enough to induce significant antibody responses in mice [115]. It was proposed that the use of vaccinia virus-based vaccines may be hindered by issues of safety regarding vaccinia virus itself, as well as its poor replication ability in avian cells [116]. In another study, a baculovirusbased vector was used to express the S1-glycoprotein of Korean nephropathogenic KM91 strain. Immunization of chickens with the KM91 vaccine resulted in 50\% kidney protection following a homologous challenge [89]. Similarly, an S1-glycoprotein of IBV has been expressed in a transgenic potato under the control of a cauliflower mosaic virus (35S) promoter gene. This success could be useful in designing food-based oral IB vaccines for use in poultry [117].

An improved "BacMam" virus surface display technology, a modified strategy from baculovirus vectoring, was used recently to display the S1-glycoprotein of IBV-M41 serotype. Subsequent experimental trials with the vaccine resulted in significant humoral and cell-mediated immune responses. About $83 \%$ of the challenged birds were shown to be protected, which is comparable to $89 \%$ protection obtained in birds immunized with commercial inactivated vaccine [118]. 
5.2. Delivery System. The route of administration and delivery method used in vaccination may affect vaccine-induced immune responses, antigen presentation, and type of $\mathrm{MHC}$ molecule involved in the resultant response. Live attenuated IB vaccines have gained wide application via injection orally and through aeronasal spray. Killed or inactivated DNA vaccines and peptide-based vaccines are commonly used via injection routes. Some improved methods have been used to deliver recombinant proteins, plasmid DNA, and peptide vaccine. For example, an IBV-DNA vaccine carrying S1- and/or N-protein of IBV has been delivered orally using attenuated Salmonella enterica serovar Typhimurium strain. Interestingly, both humoral and mucosal immune responses were shown to significantly increase following oral and intranasal immunization. Vaccinated chickens were protected against homologous challenge [119]. Other approaches recorded success using a Lactococcus lactis bacterial system to deliver IBV vaccine, and this approach led to an efficient mucosal immune response $[99,100]$.

Virus-like particle (VLP) has been a new focus of interest in vaccine development. This technology utilizes the immunogenic properties of a live virus without potential to retain pathogenic effects [120]. A VLP-based IBV vaccine has been developed using the IBV-M- and IBV-S-genes. Immunization of mice with the candidate vaccines demonstrated high levels of cell-mediated immunity, comparable with the results obtained using H120 live attenuated virus vaccine. Similarly, a chimeric VLP vaccine has been synthesized using $\mathrm{M} 1$ protein of avian influenza $\mathrm{H} 5 \mathrm{~N} 1$ virus and fusion protein "NA/S1" derived from IBV-S1 protein and the cytoplasmic and transmembrane domains of $\mathrm{H} 5 \mathrm{~N} 1$ avian influenza NA protein. The chimeric vaccine induced significant S1-specific antibodies in mice and chickens, neutralizing antibody in chickens, and increased IL-4 secretion in immunized mice [121]. Putting together these findings, there is a huge potential for VLP-based vaccines as innovative candidate and their use may provide a delivery system for the newer IBV vaccine [120].

\section{Conclusion}

Despite spending huge amounts of money to control IB, outbreaks involving classical and newly emerging virus serotypes are constantly reported. The increasing emergence of IBV genotypes and lack of cross protective immunity have augmented the pace of interest in the development of novel IBV vaccines. Though live attenuated vaccines are still common in the field, their modification, for example, through reverse genetic technology, will be useful for reducing the effects of reversion to virulence. Viral vector vaccines have the potential to facilitate efficient protein antigen production and evoke effective immune response. However, as with live attenuated vaccines, effects of neutralization by maternal antibodies are of major concern regarding the use of vectorbased vaccines, since vaccination of parent poultry breeders is practiced routinely. There is no doubt that newer generation vaccines such as the recombinant vector DNA vaccines, plasmid DNA vaccines, and multiepitope vaccines may stand as future alternatives as these vaccines have potential to deliver numerous antigens, thus producing broad-based antibody and cell-mediated immune response against numerous serotypes. Importantly, use of plasmid DNA vaccines circumvents the effect of neutralization by preexisting immunity, and their mode of action could be enhanced by delivery through different routes such as the mucosal and in ovo routes as well as the use of novel delivery methods such as nanoparticles and VLPs. In any case, future IBV vaccines must induce broad protection against different IBV serotypes, overcome maternal immunity, meet international safety regulations, and be easier to apply and cost effective for wider acceptance by poultry industry.

\section{List of Abbreviations}

CTL: $\quad$ Cytotoxic T lymphocytes

MIP-1 $\beta$ : Macrophage inflammatory protein $1 \beta$

JAK/STAT: Janus kinase/signal transducers and activators of transcription

MYD88: Myeloid differentiation primary response gene 88

IRF1: Interferon regulatory factor 1

$\mathrm{NF} \kappa \mathrm{B} 2: \quad$ Nuclear factor NF-kappa-B p100.

\section{Conflict of Interests}

Mention of trade names or commercial products in this paper is solely for the purpose of providing specific information and does not imply recommendation or endorsement by authors or their affiliated institute. The authors have no conflict of interests.

\section{Acknowledgments}

The authors would like to thank the Ministry of Science, Technology and Innovation (MOSTI) and Ministry of Education (MOE), Malaysia, for funding supports. They thank Dennis Lawler for editing this paper.

\section{References}

[1] A. Schalk and M. Hawn, "An apparently new respiratory disease of baby chicks," Journal of the American Veterinary Medical Association, vol. 78, no. 413-422, p. 19, 1931.

[2] D. Cavanagh, "Coronavirus avian infectious bronchitis virus," Veterinary Research, vol. 38, no. 2, pp. 281-297, 2007.

[3] J. J. S. de Wit, J. K. A. Cook, and H. M. J. F. van der Heijden, "Infectious bronchitis virus variants: a review of the history, current situation and control measures," Avian Pathology, vol. 40, no. 3, pp. 223-235, 2011.

[4] M. G. R. Matthijs, J. H. H. Van Eck, W. J. M. Landman, and J. A. Stegeman, "Ability of Massachusetts-type infectious bronchitis virus to increase colibacillosis susceptibility in commercial broilers: a comparison between vaccine and virulent field virus," Avian Pathology, vol. 32, no. 5, pp. 473-481, 2003.

[5] E. N. T. Meeusen, J. Walker, A. Peters, P.-P. Pastoret, and G. Jungersen, "Current status of veterinary vaccines," Clinical Microbiology Reviews, vol. 20, no. 3, pp. 489-510, 2007. 
[6] J. J. De Wit, "Detection of infectious bronchitis virus," Avian Pathology, vol. 29, no. 2, pp. 71-93, 2000.

[7] E. T. McKinley, D. A. Hilt, and M. W. Jackwood, "Avian coronavirus infectious bronchitis attenuated live vaccines undergo selection of subpopulations and mutations following vaccination," Vaccine, vol. 26, no. 10, pp. 1274-1284, 2008.

[8] E. T. McKinley, M. W. Jackwood, D. A. Hilt et al., "Attenuated live vaccine usage affects accurate measures of virus diversity and mutation rates in avian coronavirus infectious bronchitis virus," Virus Research, vol. 158, no. 1-2, pp. 225-234, 2011.

[9] Z. H. Mahmood, R. R. Sleman, and A. U. Uthman, "Isolation and molecular characterization of Sul/01/09 avian infectious bronchitis virus, indicates the emergence of a new genotype in the Middle East," Veterinary Microbiology, vol. 150, no. 1-2, pp. 21-27, 2011.

[10] Y. A. Bochkov, G. V. Batchenko, L. O. Shcherbakova, A. V. Borisov, and V. V. Drygin, "Molecular epizootiology of avian infectious bronchitis in Russia," Avian Pathology, vol. 35, no. 5, pp. 379-393, 2006.

[11] M. S. Beato, C. de Battisti, C. Terregino, A. Drago, I. Capua, and G. Ortali, "Evidence of circulation of a Chinese strain of infectious bronchitis virus (QXIBV) in Italy," Veterinary Record, vol. 156, no. 22, p. 720, 2005.

[12] K. J. Worthington, R. J. W. Currie, and R. C. Jones, "A reverse transcriptase-polymerase chain reaction survey of infectious bronchitis virus genotypes in Western Europe from 2002 to 2006," Avian Pathology, vol. 37, no. 3, pp. 247-257, 2008.

[13] R. M. Irvine, W. J. Cox, V. Ceeraz et al., "Poultry health: detection of IBV QX in commercial broiler flocks in the UK," Veterinary Record, vol. 167, no. 22, pp. 877-879, 2010.

[14] B. Sigrist, K. Tobler, M. Schybli et al., "Detection of Avian coronavirus infectious bronchitis virus type QX infection in Switzerland," Journal of Veterinary Diagnostic Investigation, vol. 24, no. 6, pp. 1180-1183, 2012.

[15] M. M. Lai and D. Cavanagh, "The molecular biology of coronaviruses," Advances in Virus Research, vol. 48, pp. 1-100, 1997.

[16] M. W. Jackwood, D. Hall, and A. Handel, "Molecular evolution and emergence of avian gammacoronaviruses," Infection, Genetics and Evolution, vol. 12, no. 6, pp. 1305-1311, 2012.

[17] B. Hogue and C. Machamer, "Coronavirus structural proteins and virus assembly," in Nidoviruses, pp. 179-200, 2008.

[18] C. A. M. de Haan and P. J. M. Rottier, "Molecular interactions in the assembly of coronaviruses," Advances in Virus Research, vol. 64, pp. 165-230, 2005.

[19] D. Cavanagh, "Coronavirus IBV: structural characterization of the spike protein," Journal of General Virology, vol. 64, no. 12, pp. 2577-2583, 1983.

[20] S. Belouzard, J. K. Millet, B. N. Licitra, and G. R. Whittaker, "Mechanisms of coronavirus cell entry mediated by the viral spike protein," Viruses, vol. 4, no. 6, pp. 1011-1033, 2012.

[21] J. Ignjatovic and P. G. McWaters, "Monoclonal antibodies to three structural proteins of avian infectious bronchitis virus: characterization of epitopes and antigenic differentiation of Australian strains," Journal of General Virology, vol. 72, no. 12, pp. 2915-2922, 1991.

[22] J. Ignjatovic and S. Sapats, "Identification of previously unknown antigenic epitopes on the $\mathrm{S}$ and $\mathrm{N}$ proteins of avian infectious bronchitis virus," Archives of Virology, vol. 150, no. 9, pp. 1813-1831, 2005.
[23] S. Shen, Z. L. Wen, and D. X. Liu, "Emergence of a coronavirus infectious bronchitis virus mutant with a truncated $3 \mathrm{~b}$ gene: functional characterization of the $3 \mathrm{~b}$ protein in pathogenesis and replication," Virology, vol. 311, no. 1, pp. 16-27, 2003.

[24] R. Casais, M. Davies, D. Cavanagh, and P. Britton, "Gene 5 of the avian coronavirus Infectious bronchitis virus is not essential for replication," Journal of Virology, vol. 79, no. 13, pp. 8065-8078, 2005.

[25] S. Youn, E. W. Collisson, and C. E. Machamer, "Contribution of trafficking signals in the cytoplasmic tail of the infectious bronchitis virus spike protein to virus infection," Journal of Virology, vol. 79, no. 21, pp. 13209-13217, 2005.

[26] P. J. M. Rottier and J. K. Rose, "Coronavirus E1 glycoprotein expressed from cloned cDNA localizes in the Golgi region," Journal of Virology, vol. 61, no. 6, pp. 2042-2045, 1987.

[27] L. Jacobs, B. A. M. Van Der Zeijst, and M. C. Horzinek, "Characterization and translation of transmissible gastroenteritis virus mRNAs," Journal of Virology, vol. 57, no. 3, pp. 1010-1015, 1986.

[28] J. K. Locker, G. Griffiths, M. C. Horzinek, and P. J. M. Rottier, "O-glycosylation of the coronavirus M protein. Differential localization of sialyltransferases in N- and O-linked glycosylation," The Journal of Biological Chemistry, vol. 267, no. 20, pp. 14094-14101, 1992.

[29] C. A. M. de Haan, M. de Wit, L. Kuo et al., "The glycosylation status of the murine hepatitis coronavirus $\mathrm{M}$ protein affects the interferogenic capacity of the virus in vitro and its ability to replicate in the liver but not the brain," Virology, vol. 312, no. 2, pp. 395-406, 2003.

[30] K. Narayanan, A. Maeda, J. Maeda, and S. Makino, "Characterization of the coronavirus $\mathrm{M}$ protein and nucleocapsid interaction in infected cells," Journal of Virology, vol. 74, no. 17, pp. 8127-8134, 2000.

[31] K. R. Hurst, R. Ye, S. J. Goebel, P. Jayaraman, and P. S. Masters, "An interaction between the nucleocapsid protein and a component of the replicase-transcriptase complex is crucial for the infectivity of coronavirus genomic RNA," Journal of Virology, vol. 84, no. 19, pp. 10276-10288, 2010.

[32] J. Jayaram, S. Youn, and E. W. Collisson, “The virion N protein of infectious bronchitis virus is more phosphorylated than the N protein from infected cell lysates," Virology, vol. 339, no. 1, pp. 127-135, 2005.

[33] S. H. Seo, L. Wang, R. Smith, and E. W. Collisson, "The carboxylterminal 120-residue polypeptide of infectious bronchitis virus nucleocapsid induces cytotoxic $\mathrm{T}$ lymphocytes and protects chickens from acute infection," Journal of Virology, vol. 71, no. 10, pp. 7889-7894, 1997.

[34] E. W. Collisson, J. Pei, J. Dzielawa, and S. H. Seo, "Cytotoxic T lymphocytes are critical in the control of infectious bronchitis virus in poultry," Developmental \& Comparative Immunology, vol. 24, no. 2-3, pp. 187-200, 2000.

[35] D. Yu, Z. Han, J. Xu et al., "A novel B-cell epitope of avian infectious bronchitis virus N protein," Viral Immunology, vol. 23, no. 2, pp. 189-199, 2010.

[36] E. Corse and C. E. Machamer, "The cytoplasmic tails of infectious bronchitis virus $\mathrm{E}$ and $\mathrm{M}$ proteins mediate their interaction," Virology, vol. 312, no. 1, pp. 25-34, 2003.

[37] L. Wilson, P. Gage, and G. Ewart, "Hexamethylene amiloride blocks E protein ion channels and inhibits coronavirus replication," Virology, vol. 353, no. 2, pp. 294-306, 2006.

[38] C.-W. Lee, D. A. Hilt, and M. W. Jackwood, “Typing of field isolates of infectious bronchitis virus based on the sequence of 
the hypervariable region in the S1 gene," Journal of Veterinary Diagnostic Investigation, vol. 15, no. 4, pp. 344-348, 2003.

[39] J. Ignjatovic and L. Galli, "The S1 glycoprotein but not the $\mathrm{N}$ or $\mathrm{M}$ proteins of avian infectious bronchitis virus induces protection in vaccinated chickens," Archives of Virology, vol. 138, no. 1-2, pp. 117-134, 1994.

[40] J. G. Zhu, H. D. Qian, Y. L. Zhang, X. G. Hua, and Z. L. Wu, "Analysis of similarity of the S1 gene in infectious bronchitis virus (IBV) isolates in Shanghai, China," Archivos de Medicina Veterinaria, vol. 39, no. 3, pp. 223-228, 2007.

[41] I. Capua, Z. Minta, E. Karpinska et al., "Co-circulation of four types of infectious bronchitis virus (793/B, 624/I, B1648 and Massachusetts)," Avian Pathology, vol. 28, no. 6, pp. 587-592, 1999.

[42] D. Cavanagh, K. Mawditt, P. Britton, and C. J. Naylor, "Longitudinal field studies of infectious bronchitis virus and avian pneumovirus in broilers using type-specific polymerase chain reactions," Avian Pathology, vol. 28, no. 6, pp. 593-605, 1999.

[43] W. Jia, K. Karaca, C. R. Parrish, and S. A. Naqi, "A novel variant of avian infectious bronchitis virus resulting from recombination among three different strains," Archives of Virology, vol. 140, no. 2, pp. 259-271, 1995.

[44] M. F. Ducatez, A. M. Martin, A. A. Owoade et al., "Characterization of a new genotype and serotype of infectious bronchitis virus in Western Africa," Journal of General Virology, vol. 90, no. 11, pp. 2679-2685, 2009.

[45] E. Domingo and J. J. Holland, "RNA virus mutations and fitness for survival," Annual Review of Microbiology, vol. 51, pp. 151-178, 1997.

[46] T.-H. Lim, H.-J. Lee, D.-H. Lee et al., "An emerging recombinant cluster of nephropathogenic strains of avian infectious bronchitis virus in Korea," Infection, Genetics and Evolution, vol. 11, no. 3, pp. 678-685, 2011.

[47] J. G. Kusters, E. J. Jager, H. G. M. Niesters, and B. A. M. van der Zeijst, "Sequence evidence for RNA recombination in field isolates of avian coronavirus infectious bronchitis virus," Vaccine, vol. 8, no. 6, pp. 605-608, 1990.

[48] C. Rowe, S. Baker, M. Nathan, J. Sgro, A. Palmenberg, and J. Fleming, "Quasispecies development by high frequency RNA recombination during MHV persistence," in Coronaviruses and Arteriviruses, pp. 759-765, Springer US, 1998.

[49] W. A. Nix, D. S. Troeber, B. F. Kingham, C. L. Keeler Jr., and J. Gelb Jr., "Emergence of subtype strains of the Arkansas serotype of infectious bronchitis virus in Delmarva broiler chickens," Avian Diseases, vol. 44, no. 3, pp. 568-581, 2000.

[50] S. W. Thor, D. A. Hilt, J. C. Kissinger, A. H. Paterson, and M. W. Jackwood, "Recombination in avian gamma-coronavirus infectious bronchitis virus," Viruses, vol. 3, no. 9, pp. 1777-1799, 2011.

[51] R. A. Gallardo, V. L. van Santen, and H. Toro, "Effects of chicken anaemia virus and infectious bursal disease virus-induced immunodeficiency on infectious bronchitis virus replication and genotypic drift," Avian Pathology, vol. 41, no. 5, pp. 451-458, 2012.

[52] S. P. Mondal and S. A. Naqi, "Maternal antibody to infectious bronchitis virus: its role in protection against infection and development of active immunity to vaccine," Veterinary Immunology and Immunopathology, vol. 79, no. 1-2, pp. 31-40, 2001.

[53] L. Vervelde, M. G. R. Matthijs, D. A. van Haarlem, J. J. de Wit, and C. A. Jansen, "Rapid NK-cell activation in chicken after infection with infectious bronchitis virus M41," Veterinary Immunology and Immunopathology, vol. 151, no. 3-4, pp. 337341, 2013.

[54] O. Takeuchi and S. Akira, "Innate immunity to virus infection," Immunological Reviews, vol. 227, no. 1, pp. 75-86, 2009.

[55] T. Okabayashi, H. Kariwa, S.-I. Yokota et al., "Cytokine regulation in SARS coronavirus infection compared to other respiratory virus infections," Journal of Medical Virology, vol. 78, no. 4, pp. 417-424, 2006.

[56] J. Pei, M. J. Sekellick, P. I. Marcus, I.-S. Choi, and E. W. Collisson, "Chicken interferon type I inhibits infectious bronchitis virus replication and associated respiratory illness," Journal of Interferon \& Cytokine Research, vol. 21, no. 12, pp. 1071-1077, 2001.

[57] K. Otsuki, Y. Sakagami, and M. Tsubokura, "Serological relationship among ten strains of avian infectious bronchitis virus," Acta Virologica, vol. 31, no. 2, pp. 138-145, 1987.

[58] S. Akira, K. Takeda, and T. Kaisho, "Toll-like receptors: critical proteins linking innate and acquired immunity," Nature Immunology, vol. 2, no. 8, pp. 675-680, 2001.

[59] M. Miettinen, T. Sareneva, I. Julkunen, and S. Matikainen, "IFNs activate toll-like receptor gene expression in viral infections," Genes \& Immunity, vol. 2, no. 6, pp. 349-355, 2001.

[60] A. M. Kameka, S. Haddadi, D. S. Kim, S. C. Cork, and M. F. Abdul-Careem, "Induction of innate immune response following infectious bronchitis corona virus infection in the respiratory tract of chickens," Virology, vol. 450-451, pp. 114-121, 2014.

[61] F. Cong, X. Liu, Z. Han, Y. Shao, X. Kong, and S. Liu, "Transcriptome analysis of chicken kidney tissues following coronavirus avian infectious bronchitis virus infection," $B M C$ Genomics, vol. 14, no. 1, article 743, 2013.

[62] A. Dar, A. Potter, S. Tikoo et al., "CpG oligodeoxynucleotides activate innate immune response that suppresses infectious bronchitis virus replication in chicken embryos," Avian Diseases, vol. 53, no. 2, pp. 261-267, 2009.

[63] X. Guo, A. J. M. Rosa, D.-G. Chen, and X. Wang, "Molecular mechanisms of primary and secondary mucosal immunity using avian infectious bronchitis virus as a model system," Veterinary Immunology and Immunopathology, vol. 121, no. 34, pp. 332-343, 2008.

[64] J. Guo, D. J. Hui, W. C. Merrick, and G. C. Sen, “A new pathway of translational regulation mediated by eukaryotic initiation factor 3," The EMBO Journal, vol. 19, no. 24, pp. 6891-6899, 2000.

[65] J. H. Darbyshire and R. W. Peters, "Humoral antibody response and assessment of protection following primary vaccination of chicks with maternally derived antibody against avian infectious bronchitis virus," Research in Veterinary Science, vol. 38, no. 1, pp. 14-21, 1985.

[66] L. F. Caron, "Etiology and immunology of infectious bronchitis virus," Revista Brasileira de Ciencia Avicola, vol. 12, no. 2, pp. 115-119, 2010.

[67] S. H. Seo, J. Pei, W. E. Briles, J. Dzielawa, and E. W. Collisson, "Adoptive transfer of infectious bronchitis virus primed $\alpha \beta \mathrm{T}$ cells bearing CD8 antigen protects chicks from acute infection," Virology, vol. 269, no. 1, pp. 183-189, 2000.

[68] L. M. Timms and C. D. Bracewell, "Cell mediated and humoral immune response of chickens to live infectious bronchitis vaccines," Research in Veterinary Science, vol. 31, no. 2, pp. 182$189,1981$.

[69] M. A. Johnson, C. Pooley, J. Ignjatovic, and S. G. Tyack, "A recombinant fowl adenovirus expressing the $\mathrm{S} 1$ gene of infectious bronchitis virus protects against challenge with infectious 
bronchitis virus," Vaccine, vol. 21, no. 21-22, pp. 2730-2736, 2003.

[70] J. Pardo, A. Bosque, R. Brehm et al., "Apoptotic pathways are selectively activated by granzyme A and/or granzyme B in CTLmediated target cell lysis," The Journal of Cell Biology, vol. 167, no. 3, pp. 457-468, 2004.

[71] R. S. Gurjar, S. L. Gulley, and F. W. van Ginkel, "Cell-mediated immune responses in the head-associated lymphoid tissues induced to a live attenuated avian coronavirus vaccine," Developmental and Comparative Immunology, vol. 41, no. 4, pp. 715722, 2013.

[72] R. Meir, S. Krispel, L. Simanov, D. Eliahu, O. Maharat, and J. Pitcovski, "Immune responses to mucosal vaccination by the recombinant S1 and N proteins of infectious bronchitis virus," Viral Immunology, vol. 25, no. 1, pp. 55-62, 2012.

[73] D. Cavanagh, "Severe acute respiratory syndrome vaccine development: experiences of vaccination against avian infectious bronchitis coronavirus," Avian Pathology, vol. 32, no. 6, pp. 567-582, 2003.

[74] D. King and D. Cavanagh, "Infectious bronchitis," Diseases of Poultry, vol. 9, pp. 471-484, 1991.

[75] H. J. Lee, H. N. Youn, J. S. Kwon et al., "Characterization of a novel live attenuated infectious bronchitis virus vaccine candidate derived from a Korean nephropathogenic strain," Vaccine, vol. 28, no. 16, pp. 2887-2894, 2010.

[76] J. Sasipreeyajan, T. Pohuang, and N. Sirikobkul, "Efficacy of different vaccination programs against thai QX-like infectious bronchitis virus," Thai Journal of Veterinary Medicine, vol. 42, no. 1, pp. 73-79, 2012.

[77] A. Vagnozzi, M. García, S. M. Riblet, and G. Zavala, "Protection induced by infectious laryngotracheitis virus vaccines alone and combined with Newcastle disease virus and/or infectious bronchitis virus vaccines," Avian Diseases, vol. 54, no. 4, pp. 1210-1219, 2010.

[78] I. Tarpey, S. J. Orbell, P. Britton et al., "Safety and efficacy of an infectious bronchitis virus used for chicken embryo vaccination," Vaccine, vol. 24, no. 47-48, pp. 6830-6838, 2006.

[79] G. Bijlenga, J. K. A. Cook, J. Gelb Jr., and J. J. De Wit, "Development and use of the $\mathrm{H}$ strain of avian infectious bronchitis virus from the Netherlands as a vaccine: a review," Avian Pathology, vol. 33, no. 6, pp. 550-557, 2004.

[80] Y. Zhang, H.-N. Wang, T. Wang et al., "Complete genome sequence and recombination analysis of infectious bronchitis virus attenuated vaccine strain H120," Virus Genes, vol. 41, no. 3, pp. 377-388, 2010.

[81] S.-W. Lee, P. F. Markham, M. J. C. Coppo et al., "Attenuated vaccines can recombine to form virulent field viruses," Science, vol. 337, no. 6091, p. 188, 2012.

[82] M. G. R. Matthijs, A. Bouma, F. C. Velkers, J. H. H. van Eck, and J. A. Stegeman, "Transmissibility of infectious bronchitis virus H120 vaccine strain among broilers under experimental conditions," Avian Diseases, vol. 52, no. 3, pp. 461-466, 2008.

[83] P. S. Masters and P. J. M. Rottier, "Coronavirus reverse genetics by targeted RNA recombination," Current Topics in Microbiology and Immunology, vol. 287, pp. 133-159, 2005.

[84] Y. S. Zhou, Y. Zhang, H. N. Wang et al., "Establishment of reverse genetics system for infectious bronchitis virus attenuated vaccine strain H120," Veterinary Microbiology, vol. 162, no. 1, pp. 53-61, 2013.

[85] P. Finney, P. Box, and H. Holmes, "Studies with a bivalent infectious bronchitis killed virus vaccine," Avian Pathology, vol. 19, no. 3, pp. 435-450, 1990.
[86] B. S. Ladman, C. R. Pope, A. F. Ziegler et al., "Protection of chickens after live and inactivated virus vaccination against challenge with nephropathogenic infectious bronchitis virus PA/Wolgemuth/98," Avian Diseases, vol. 46, no. 4, pp. 938-944, 2002.

[87] J. K. A. Cook, M. Jackwood, and R. C. Jones, “The long view: 40 years of infectious bronchitis research," Avian Pathology, vol. 41, no. 3, pp. 239-250, 2012.

[88] N. Tatsis and H. C. J. Ertl, "Adenoviruses as vaccine vectors," Molecular Therapy, vol. 10, no. 4, pp. 616-629, 2004.

[89] C.-S. Song, Y.-J. Lee, C.-W. Lee et al., "Induction of protective immunity in chickens vaccinated with infectious bronchitis virus S1 glycoprotein expressed by a recombinant baculovirus," Journal of General Virology, vol. 79, no. 4, pp. 719-723, 1998.

[90] O. B. Faulkner, C. Estevez, Q. Yu, and D. L. Suarez, "Passive antibody transfer in chickens to model maternal antibody after avian influenza vaccination," Veterinary Immunology and Immunopathology, vol. 152, no. 3-4, pp. 341-347, 2013.

[91] M. T. Dertzbaugh, "Genetically engineered vaccines: an overview," Plasmid, vol. 39, no. 2, pp. 100-113, 1998.

[92] X.-M. Shi, Y. Zhao, H.-B. Gao et al., "Evaluation of recombinant fowlpox virus expressing infectious bronchitis virus S1 gene and chicken interferon- $\gamma$ gene for immune protection against heterologous strains," Vaccine, vol. 29, no. 8, pp. 1576-1582, 2011.

[93] H.-Y. Chen, M.-F. Yang, B.-A. Cui et al., "Construction and immunogenicity of a recombinant fowlpox vaccine coexpressing S1 glycoprotein of infectious bronchitis virus and chicken IL-18," Vaccine, vol. 28, no. 51, pp. 8112-8119, 2010.

[94] Z. Xiang, G. Gao, A. Reyes-Sandoval, Y. Li, J. Wilson, and $\mathrm{H}$. Ertl, "Oral vaccination of mice with adenoviral vectors is not impaired by preexisting immunity to the vaccine carrier," Journal of Virology, vol. 79, no. 6, p. 3888, 2005.

[95] M. W. Jackwood, "Current and future recombinant viral vaccines for poultry," Advances in Veterinary Medicine, vol. 41, pp. 517-522, 1999.

[96] L. Wang, R. L. Parr, D. J. King, and E. W. Collisson, "A highly conserved epitope on the spike protein of infectious bronchitis virus," Archives of Virology, vol. 140, no. 12, pp. 2201-2213, 1995.

[97] N. Promkuntod, R. E. W. van Eijndhoven, G. de Vrieze, A. Gröne, and M. H. Verheije, "Mapping of the receptorbinding domain and amino acids critical for attachment in the spike protein of avian coronavirus infectious bronchitis virus," Virology, vol. 448, pp. 26-32, 2014.

[98] T. Yang, H.-N. Wang, X. Wang et al., "The protective immune response against infectious bronchitis virus induced by multiepitope based peptide vaccines," Bioscience, Biotechnology and Biochemistry, vol. 73, no. 7, pp. 1500-1504, 2009.

[99] H.-P. Cao, H.-N. Wang, A.-Y. Zhang et al., "Expression of avian infectious bronchitis virus multi-epitope based peptide EpiC in Lactococcus lactis for oral immunization of chickens," Bioscience, Biotechnology and Biochemistry, vol. 76, no. 10, pp. 1871-1876, 2012.

[100] H.-P. Cao, H.-N. Wang, X. Yang et al., "Lactococcus lactis anchoring avian infectious bronchitis virus multi-epitope peptide EpiC induced specific immune responses in chickens," Bioscience, Biotechnology and Biochemistry, vol. 77, no. 7, pp. 1499-1504, 2013.

[101] S. Moreno and M. Timón, "DNA vaccination: an immunological perspective," Inmunologia, vol. 23, no. 1, pp. 41-55, 2004.

[102] M. A. Liu, "DNA vaccines: an historical perspective and view to the future," Immunological Reviews, vol. 239, no. 1, pp. 62-84, 2011. 
[103] D. R. Kapczynski, D. A. Hilt, D. Shapiro, H. S. Sellers, and M. W. Jackwood, "Protection of chickens from infectious bronchitis by in ovo and intramuscular vaccination with a DNA vaccine expressing the S1 glycoprotein," Avian Diseases, vol. 47, no. 2, pp. 272-285, 2003.

[104] L. Tian, H.-N. Wang, D. Lu, Y.-F. Zhang, T. Wang, and R.-M. Kang, "The immunoreactivity of a chimeric multi-epitope DNA vaccine against IBV in chickens," Biochemical and Biophysical Research Communications, vol. 377, no. 1, pp. 221-225, 2008.

[105] M. Tang, H. Wang, S. Zhou, and G. Tian, "Enhancement of the immunogenicity of an infectious bronchitis virus DNA vaccine by a bicistronic plasmid encoding nucleocapsid protein and interleukin-2," Journal of Virological Methods, vol. 149, no. 1, pp. 42-48, 2008.

[106] B. Tan, H. Wang, L. Shang, and T. Yang, "Coadministration of chicken GM-CSF with a DNA vaccine expressing infectious bronchitis virus (IBV) S1 glycoprotein enhances the specific immune response and protects against IBV infection," Archives of Virology, vol. 154, no. 7, pp. 1117-1124, 2009.

[107] F. Yan, Y. Zhao, Y. Hu et al., "Protection of chickens against infectious bronchitis virus with a multivalent DNA vaccine and boosting with an inactivated vaccine," Journal of Veterinary Science, vol. 14, no. 1, pp. 53-60, 2013.

[108] M.-J. Tang, H.-N. Wang, S. Zhou, Y. Huang, and P. Liu, "Potent immune responses elicited by a bicistronic IBV DNA vaccine expressing S1 and IL-2 gene," Wei Sheng Wu Xue Bao, vol. 47, no. 6, pp. 1055-1059, 2007.

[109] L. Haygreen, F. Davison, and P. Kaiser, "DNA vaccines for poultry: the jump from theory to practice," Expert Review of Vaccines, vol. 4, no. 1, pp. 51-62, 2005.

[110] D. Cavanagh, R. Casais, M. Armesto et al., "Manipulation of the infectious bronchitis coronavirus genome for vaccine development and analysis of the accessory proteins," Vaccine, vol. 25, no. 30, pp. 5558-5562, 2007.

[111] P. Britton, M. Armesto, D. Cavanagh, and S. Keep, "Modification of the avian coronavirus infectious bronchitis virus for vaccine development," Bioengineered Bugs, vol. 3, no. 2, pp. 114119, 2012.

[112] R. Casais, B. Dove, D. Cavanagh, and P. Britton, "Recombinant avian infectious bronchitis virus expressing a heterologous spike gene demonstrates that the spike protein is a determinant of cell tropism," Journal of Virology, vol. 77, no. 16, pp. 90849089, 2003.

[113] M. Armesto, S. Evans, D. Cavanagh, A.-B. Abu-Median, S. Keep, and P. Britton, "A recombinant Avian infectious bronchitis virus expressing a heterologous spike gene belonging to the $4 / 91$ serotype," PLoS ONE, vol. 6, no. 8, Article ID e24352, 2011.

[114] T. Hodgson, R. Casais, B. Dove, P. Britton, and D. Cavanagh, "Recombinant infectious bronchitis coronavirus Beaudette with the spike protein gene of the pathogenic M41 strain remains attenuated but induces protective immunity," Journal of Virology, vol. 78, no. 24, pp. 13804-13811, 2004.

[115] F. M. Tomley, A. P. Mockett, M. E. Boursnell et al., "Expression of the infectious bronchitis virus spike protein by recombinant vaccinia virus and induction of neutralizing antibodies in vaccinated mice," Journal of General Virology, vol. 68, part 9, pp. 2291-2298, 1987.

[116] F. M. F. Tomley, "Recombinant vaccines for poultry," Vaccine, vol. 9, no. 1, pp. 4-5, 1991.

[117] J.-Y. Zhou, J.-X. Wu, L.-Q. Cheng et al., "Expression of immunogenic S1 glycoprotein of infectious bronchitis virus in transgenic potatoes," Journal of Virology, vol. 77, no. 16, pp. 9090-9093, 2003.

[118] J. Zhang, X.-W. Chen, T.-Z. Tong, Y. Ye, M. Liao, and H.-Y. Fan, "BacMam virus-based surface display of the infectious bronchitis virus (IBV) S1 glycoprotein confers strong protection against virulent IBV challenge in chickens," Vaccine, vol. 32, no. 6, pp. 664-670, 2014.

[119] H. Jiao, Z. Pan, Y. Yin, S. Geng, L. Sun, and X. Jiao, "Oral and nasal DNA vaccines delivered by attenuated Salmonella enterica serovar typhimurium induce a protective immune response against infectious bronchitis in chickens," Clinical and Vaccine Immunology, vol. 18, no. 7, pp. 1041-1045, 2011.

[120] L. H. L. Lua, N. K. Connors, F. Sainsbury, Y. P. Chuan, N. Wibowo, and A. P. J. Middelberg, "Bioengineering virus-like particles as vaccines," Biotechnology and Bioengineering, vol. 111, no. 3, pp. 425-440, 2014.

[121] L. Lv, X. Li, G. Liu et al., "Production and immunogenicity of chimeric virus-like particles (VLPs) containing the spike (S1) glycoprotein of infectious bronchitis virus," Journal of Veterinary Science, vol. 15, no. 2, pp. 209-216, 2014. 


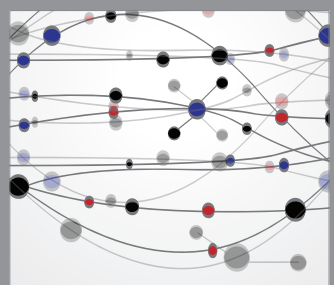

The Scientific World Journal
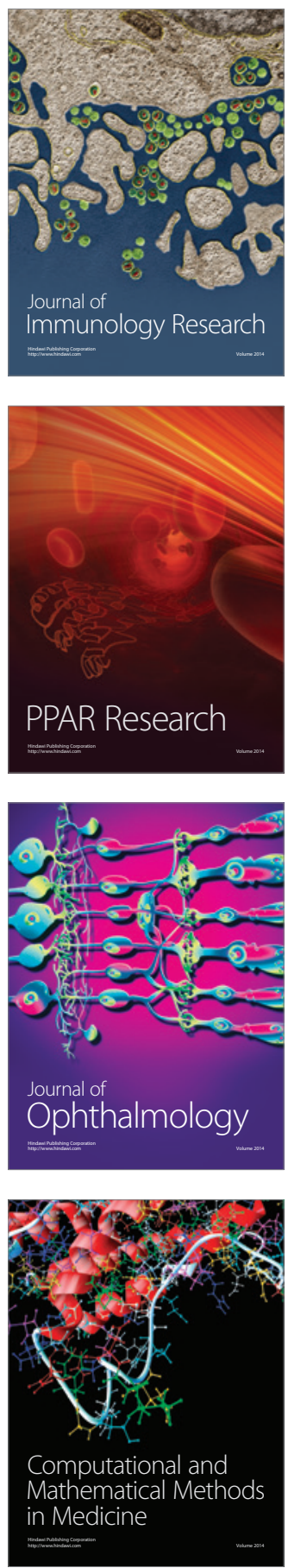

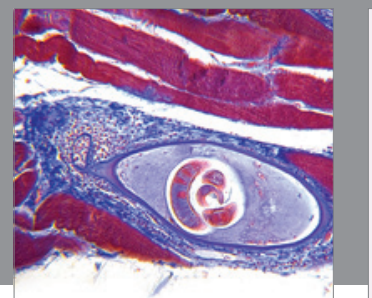

Gastroenterology

Research and Practice
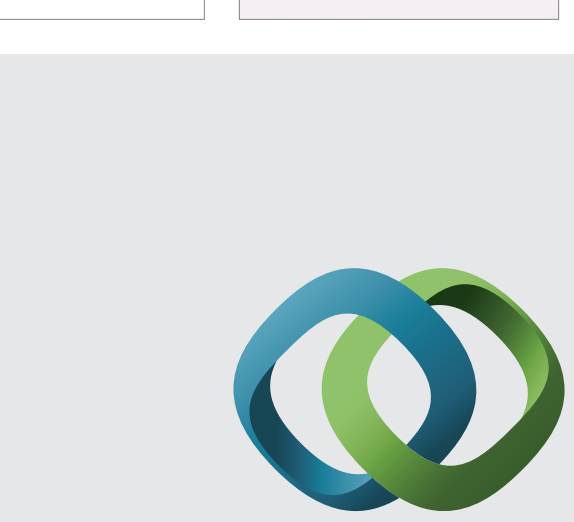

\section{Hindawi}

Submit your manuscripts at

http://www.hindawi.com
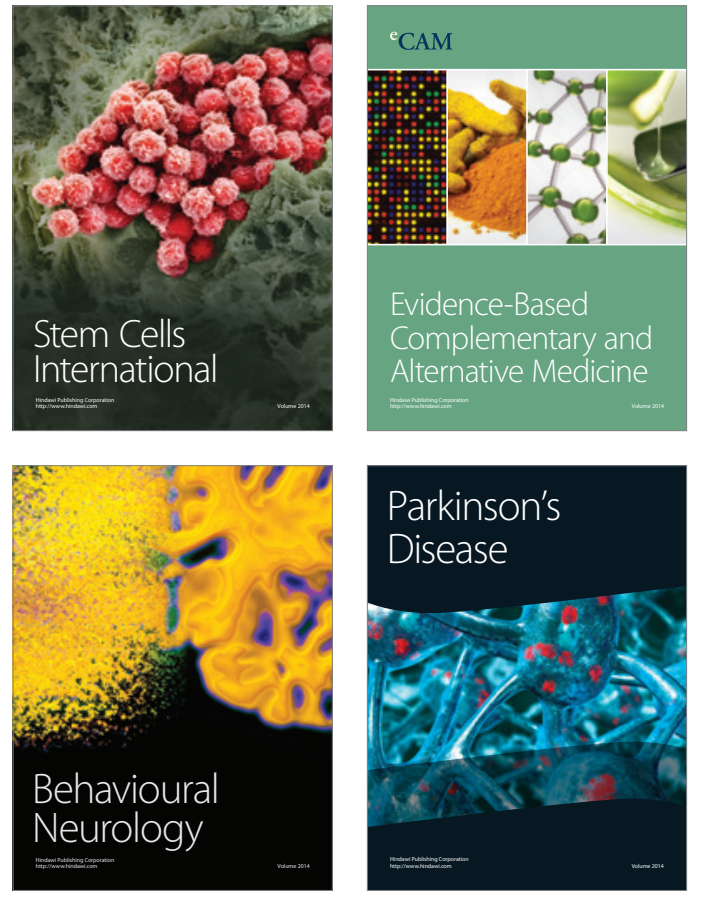
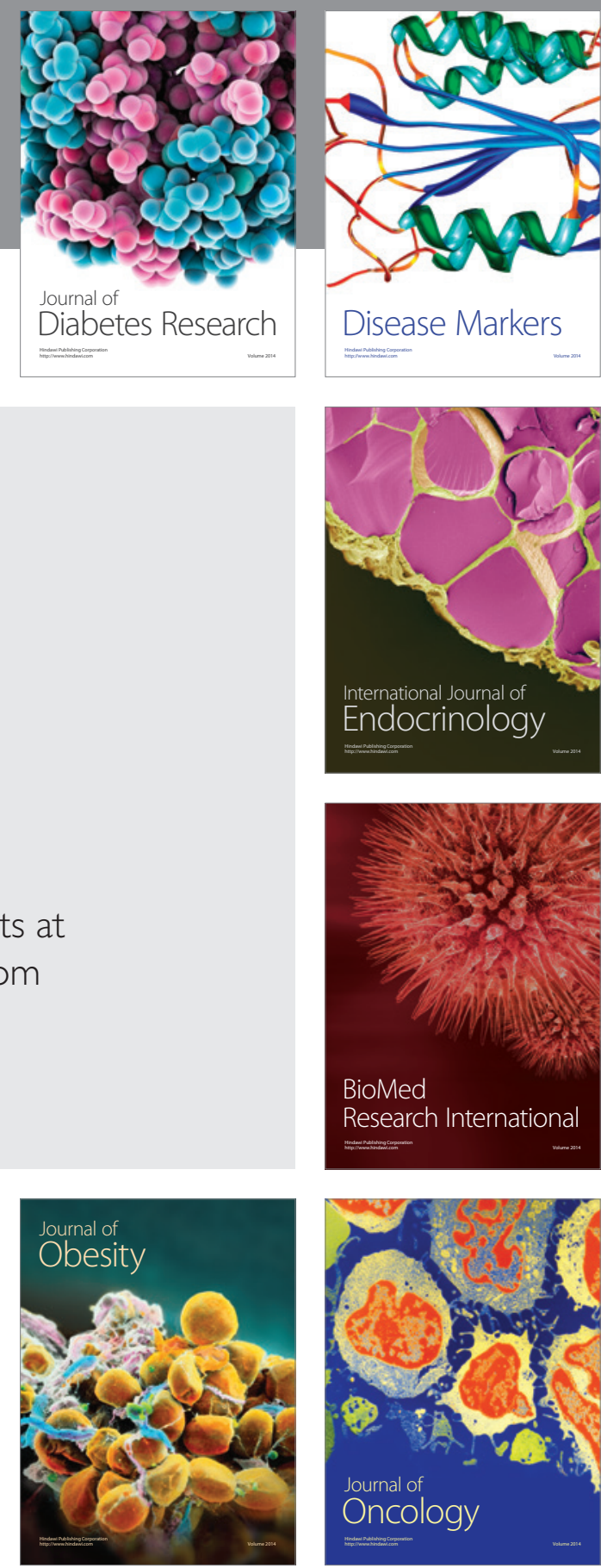

Disease Markers
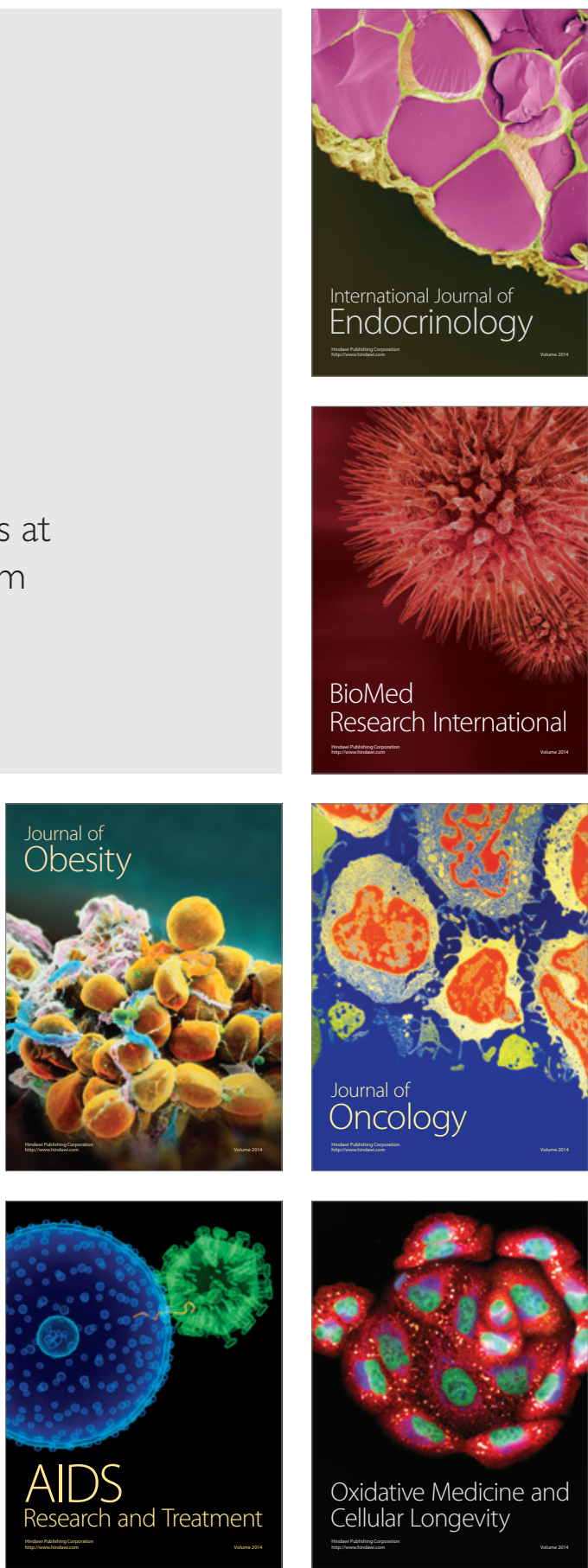